\title{
A MORPHOMETRIC STUDY OF THE PAPILLARY MUSCLES OF THE LEFT VENTRICLES OF HUMAN CADAVERIC HEARTS IN NORTH-WEST INDIAN POPULATION
}

\author{
Kirandeep Kaur Aulakh¹, Amit Kumar Saxena2, Prachi Saffar Aneja³, Savita Bansal ${ }^{4}$ \\ ${ }^{1}$ Assistant Professor, Department of Anatomy, FMHS, SGT University, Gurgaon. \\ 2 Professor and HOD, Department of Anatomy, FMHS, SGT University, Gurgaon. \\ ${ }^{3}$ Associate Professor, Department of Anatomy, FMHS, SGT University, Gurgaon. \\ ${ }_{4}^{4}$ Associate Professor, Department of Pathology, Manav Rachna Dental College, Faridabad.
}

\section{ABSTRACT}

\section{BACKGROUND}

Atrioventricular (AV) valvular apparatus comprises of AV orifice and its annulus, valvular leaflets, chordae tendineae and papillary muscles. The study was done with a purpose to find out the gross morphology of papillary muscle of left ventricle and to compare any gender differences. This is helpful in understanding left atrioventricular valve dysfunction like mitral regurgitations a nd also helpful in valve repair surgeries.

Aims of this Study

1. To note the shape, origin, number of heads and other gross features of papillary muscles of left ventricle.

2. To find out sexual difference in the gross morphology of papillary muscles of left ventricle.

\section{MATERIALS AND METHODS}

The study was carried out in 30 apparently normal cadaveric hearts after fixing in $10 \%$ formalin. The left ventricle was opened after giving an incision and gross morphology of papillary muscles of left ventricles was studied by using Vernier calliper.

Statistical analysis SPSS software and unpaired 't' test was used. P value less than 0.05 was taken as significant.

\section{RESULTS AND CONCLUSION}

It was found that both the anterolateral and posteromedial papillary muscles of left ventricle were always present. Number of heads of papillary muscles ranged from 1 to 6 in left ventricle. Length of anterolateral papillary muscle (ALPM) was more than posteromedial papillary muscle (PMPM) of left ventricle. Mixed type of ALPM was found more frequently in females (92.3\%) in the present study than in males $(58.8 \%)$. This difference was statistically significant $(\mathrm{p}<0.05)$. Posteromedial papillary muscle of the left ventricle took origin mainly from middle $1 / 3^{\text {rd }}$ of left ventricle. Such cases occurred more frequently in females than in males. The difference was statistically significant $(\mathrm{p}<0.05)$.

\section{KEYWORDS}

Left Ventricle, Papillary Muscles, Mitral Valve

HOW TO CITE THIS ARTICLE: Aulakh KK, Saxena AK, Aneja PS, et al.A morphometric study of the papillary muscles of the left ventricles of human cadaveric hearts in North-West Indian population. J. Evolution Med. Dent. Sci. 2016;5(100):7344-7352, DOI: 10.14260/Jemds/2016/1663

\section{BACKGROUND \\ Atrioventricular (AV) valvular apparatus comprises of $\mathrm{AV}$ orifice and its annulus, valvular leaflets, chordae tendineae and papillary muscles. ${ }^{1}$ Mitral valvular complex comprises of mitral AV orifice and its valvular annulus, leaflets, chordae tendineae and papillary muscles. ${ }^{2}$ Mitral AV orifice has a mean circumference of $9.0 \mathrm{~cm}$ in males and $7.2 \mathrm{~cm}$ in females. ${ }^{3}$ \\ Mitral valve leaflets are two in number. Mitral valve is now described as consisting of a continuous veil attached around entire circumference of the mitral orifice. ${ }^{4}$ Its free edge bears indentations, two are deep and regularly positioned. The tips of papillary muscle are guides to them. ${ }^{5}$ These indentations are anterolateral and posteromedial commissures.}

Financial or Other, Competing Interest: None.

Submission 10-11-2016, Peer Review 03-12-2016,

Acceptance 10-12-2016, Published 15-12-2016.

Corresponding Author:

Dr. Kirandeep Kaur Aulakh,

\# C 1/403,

The Legend, Sector 57,

Gurgaon -122001.

E-mail: kirandeep1307@gmail.com

DOI: $10.14260 /$ jemds $/ 2016 / 1663$
Left ventricular papillary muscles are two in number and vary in length and breadth. They may be bifid. Anterolateral (anterior) papillary muscle arises from the concavity of the anterolateral free wall of the left ventricle. Posteromedial (posterior) papillary muscle arises from the junction of posterior wall and interventricular septum.1,6,7

Morphologically, the papillary muscles can be classified as conical, mammillated, flat topped, grooved, stepped, wavy, arched, sloped, saucerised, two tiered, interlinked, parallel, V, Y or H-shaped. ${ }^{8}$

Papillary muscles can be classified into three broad categories depending upon the nature of attachment to ventricular wall and relative length of body of papillary muscle that protrude freely into the ventricular cavity. ${ }^{9}$

Completely tethered papillary muscles are fully adherent to subjacent ventricular myocardium and protrude very little into ventricular cavity with few trabecular attachments. Finger like papillary muscles have $1 / 3^{\text {rd }}$ or more of the body protruding freely into ventricular cavity with very few or no trabecular attachments. Part of body of mixed type papillary muscle protrudes freely into ventricular cavity but has considerable trabecular attachments and tethering also. ${ }^{9}$ 
Normal valve function depends upon the anatomic and mechanical integrity of the atrioventricular ring, the valve leaflets, the chordae tendineae and the papillary muscles, as well as upon proper integration of the time relations between contraction of the papillary muscle and contraction of the free ventricular wall. ${ }^{1}$ Papillary muscle contraction normally continues synchronously with ventricular contraction and thereby supports the chordae tendineae and prevents overshoot of the leaflets during ventricular systole. ${ }^{10}$ In papillary muscle dysfunction, contraction is absent or ineffective. Rupture of one or more chordae tendineae results in acute loss of leaflet support leading to abrupt onset of mitral regurgitation. Regurgitation also occurs in rupture of papillary muscle.6,11 Left ventricular papillary muscles appear to be the last portions of the heart to be perfused by coronary arterial blood. Therefore, they are sensitive markers of myocardial ischaemia. Foci of necrosis or fibrosis are commonly seen in them particularly in the posteromedial papillary muscle, which has a poorer blood supply than anterolateral papillary muscle. 12

The axis of papillary muscles is generally oriented in a direction parallel to the axis of the left ventricular cavity ${ }^{7}$ and is almost perpendicular to the atrioventricular ring. This orientation provides mechanical advantage in that tension developed by the papillary muscles is applied almost perpendicular to the mitral valve leaflets. ${ }^{7}$ In concentric left ventricular hypertrophy, the papillary muscles become proportionately thicker in diameter, preserving the same axial direction as in the normal heart. In dilatation of the left ventricular chamber, the dilatation predominantly involves the apical region thus causing the papillary muscles to appear to move upward toward the valve ring. ${ }^{13}$ The axis of papillary muscles in such cases is tangential to that of the ventricular chamber. This explains in part the mitral insufficiency often found with left ventricular dilatation. ${ }^{7}$ The distance between the apex and the base of the left ventricle does not shorten during contraction of the ventricle. The atrioventricular region moves upwards and backwards, but the length of the cavity remains constant. ${ }^{14}$ This makes it easier to understand how the comparatively small contraction of the papillary muscles is able to ensure efficient closure of the valve. Failure of one or both papillary muscles to shorten during the ejection phase of ventricular systole, fibrosis, and atrophy of a papillary muscle or centrifugal migration of the papillary muscles due to left ventricular dilatation result in mitral incompetence. ${ }^{1}$ In mitral valve prolapse syndrome, the left ventricle assumes various configurations, which is possibly dependent on the architecture and location of papillary muscles, subject to pull by the prolapsing leaflet. Thus, a detailed knowledge of anatomical characteristics of the papillary muscles of both the ventricles is necessary because of their clinical and surgical significance. Very few Indian studies have been done on morphometric analysis of papillary muscles. The purpose of present study is to extend concepts previously presented as well as to overcome deficiencies in our knowledge of anatomy of papillary muscles in Indian population.

\section{Aims}

1. To note the shape, origin, number of heads, length, protrusion of papillary muscles of left ventricle.

2. To find out sexual difference in the gross morphology of papillary muscles of left ventricle.

\section{MATERIALS AND METHODS}

The present study was carried out in 30 apparently normal cadaveric hearts, which were available in the museum of the Department of Anatomy, Govt. Medical College and Hospital and Postgraduate Institute of Medical Education and Research, Chandigarh. The ages of the cases ranged from 17 to 75 years. There were 17 male and 13 female hearts. The hearts, which were fixed in $10 \%$ formalin, were washed under running tap water. As the study was done in the donated cadavers which were used for MBBS teaching and dissection, all the ethical clearances were taken before the start of the study.

\section{Inclusion Criteria}

Apparently normal looking cadaveric hearts of age 17 to 75 years were included in the study.

\section{Exclusion Criteria}

Any grossly visible abnormal heart or diseased hearts were excluded from the study.

The heart was opened along its left border (obtuse margin) to avoid injury to the papillary muscles. The mitral valve was cut through mid-region of the posterior leaflet. The hearts were opened and washed under running tap water to remove blood clots. Gross morphology of the papillary muscles of the ventricles was studied.

Morphology of the papillary muscles of the left ventricle was noted which included number of heads, length, shape, origin and other gross features. The papillary muscles were studied and measured in situ with the help of a Vernier calliper. A head of a papillary muscle is defined as a muscle that is directly attached to the ventricular wall and its length was measured from this origin to the highest point of the muscle. The maximum length was taken. All measurements were made twice and the mean values were recorded. The site of the origin of the papillary muscles from the ventricular wall was also observed.

The values obtained from various measurements were tabulated and averages were calculated. Statistical analysis was done using unpaired ' $t$ ' test to compare lengths of papillary muscles . The present observations were compared with the other studies available in the literature to note any differences.

\section{RESULTS}

The measurements of left ventricular papillary muscles are listed in Table 1.

\section{Anterolateral Papillary Muscle (ALPM):}

- ALPM arises from sternocostal mural myocardium.

- ALPM was present in all cases.

Number of heads of ALPM ranged from 1 to 3. Single head was present more frequently. Incidence of single head was more in males (70.6\%) than in females (53.8\%). Double head was present in $29.4 \%$ cases in males and $38.5 \%$ cases in females. 3 heads were present in only one female heart (Table 2).

Mean length of ALPM was $24.55 \mathrm{~mm}$ with a range of 8.3 to $45.5 \mathrm{~mm}$. Mean length of ALPM was more in males $(25.99 \mathrm{~mm})$ than in females $(22.97 \mathrm{~mm}$ ). The mean length of anterolateral papillary muscles decreased as the number of heads increased (Table 3). 
ALPM took origin mainly from middle $1 / 3^{\text {rd }}$ of left ventricle (52.4\%). Number of cases taking origin from middle $1 / 3^{\text {rd }}$ of left ventricle was more in females (55\%) as compared to that in males $(50 \%)$. ALPM took origin from lower $1 / 3^{\text {rd }}$ of left ventricle in $50 \%$ cases in males and $35 \%$ cases in females. ALPM arose from upper $1 / 3^{\text {rd }}$ of left ventricle in $10 \%$ cases in females only but not in males.
Muscle bellies were predominantly mixed type (73.3\%). Mixed types of bellies were more in females (92.3\%) than in males (58.8\%). Rest of the muscle bellies were intraluminal or sessile. The difference was statistically significant $(\mathrm{p}<0.05)$.

The shape of muscle bellies was predominantly flat topped (26.7\%), mammillated (20\%) and interlinked (20\%). The rest of the bellies were grooved, stepped, sloped, two tiered (Fig.1), $\mathrm{H}$ shaped and two tiered +1 separate. In one case, ALPM was muscular up to its end on the left ventricular wall (Fig.2).

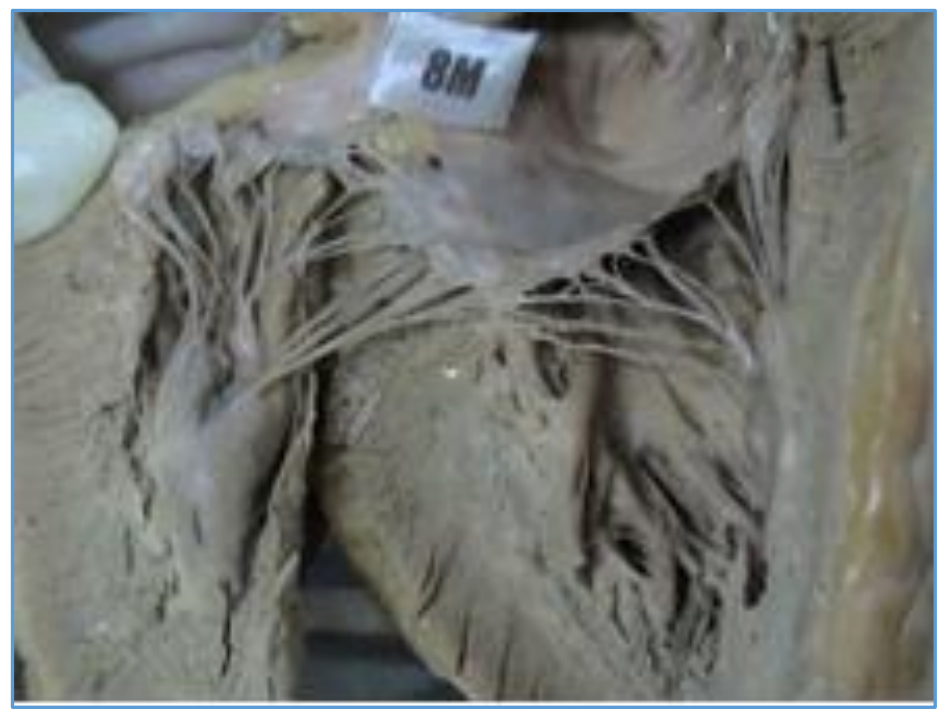

Figure 1. 2-Tiered Anterolateral Papillary Muscle of Left Ventricle on Left Side of the Figure

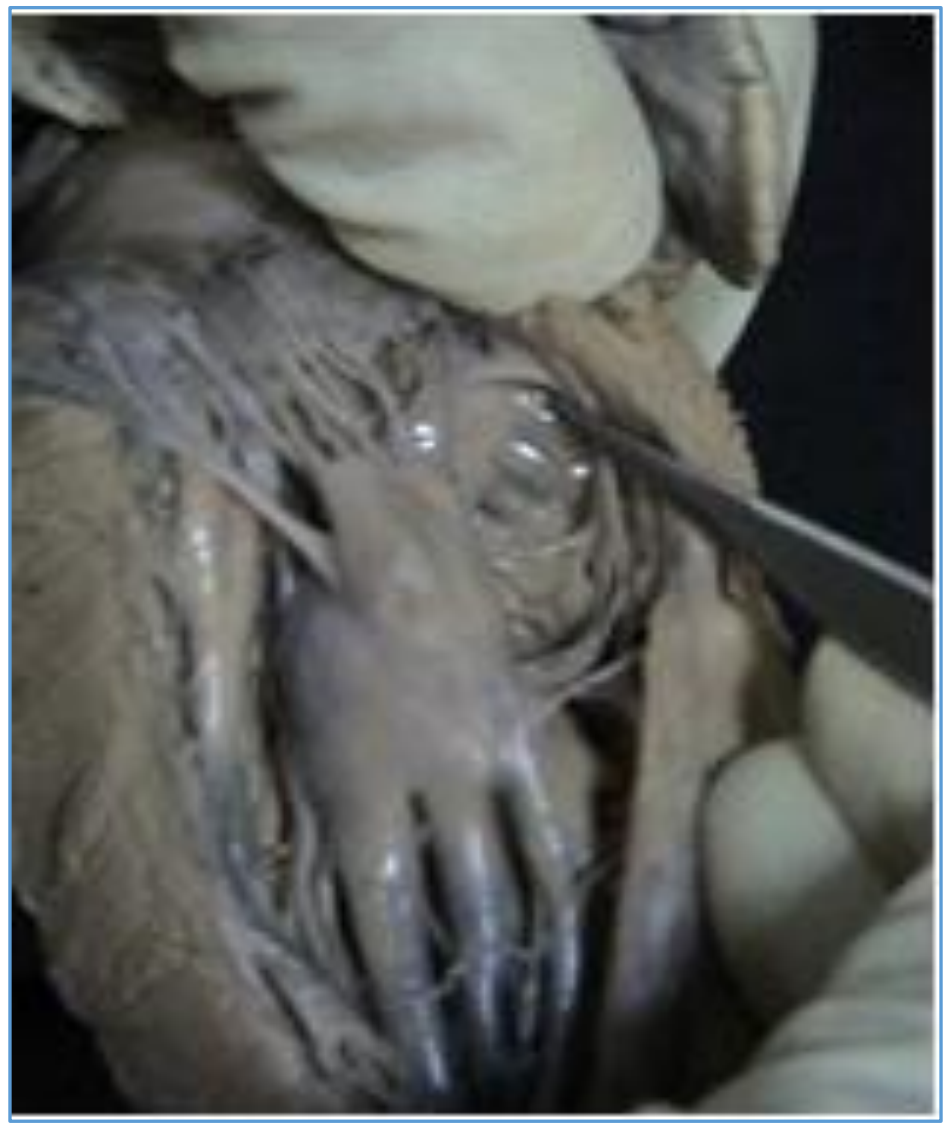

Figure 2. Anterolateral Papillary Muscle going to the Left Ventricular Wall and Muscular up to its End 


\section{Posteromedial Papillary Muscle (PMPM)}

PMPM arises from the diaphragmatic region of left ventricle. It was present in all cases.

Number of heads of PMPM ranged from 1 to 6. Single head was present in $47.1 \%$ cases in males and $30.8 \%$ cases in females. Double head was present in $29.4 \%$ cases in males and $23.0 \%$ cases in females. 3 heads were seen in $17.6 \%$ males and
$30.8 \%$ females, 4 heads in $5.9 \%$ males and $7.7 \%$ females. A case of 6 heads in a female was found (Table 2, Fig. 3).

Mean length of PMPM was more in males $(22.60 \mathrm{~mm})$ than in females $(16.91 \mathrm{~mm})$. The difference was statistically significant $(\mathrm{p}<0.05)$ (Table 1$)$. The mean length of PMPM was found to decrease as the number of heads increased (Table 2).

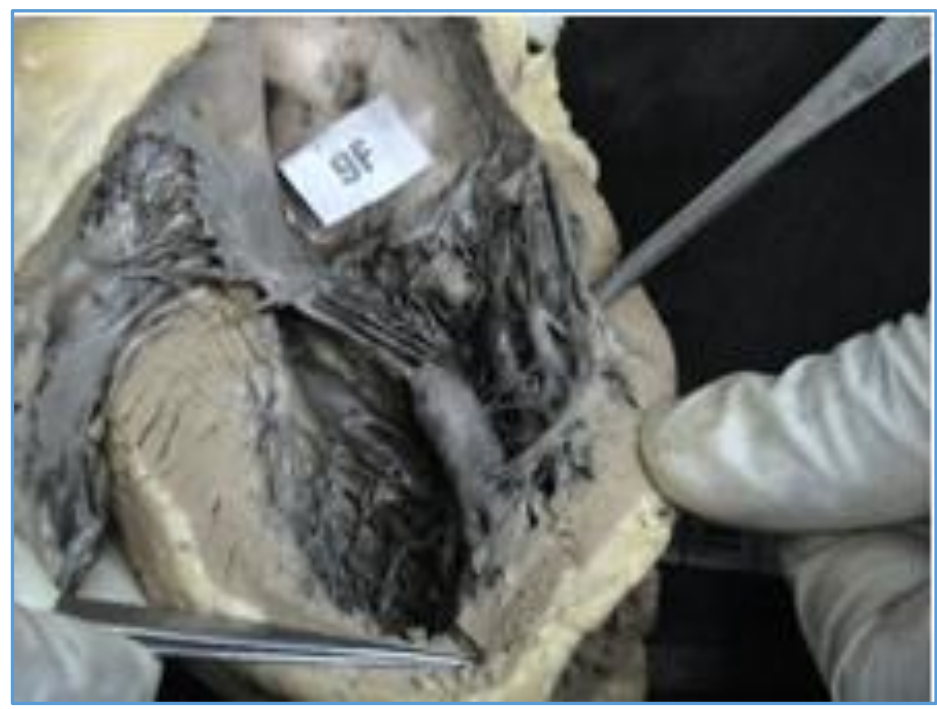

Figure 3. A Case of Six Posteromedial Papillary Muscles in a Female Heart, Four Muscles Visible in the Figure

PMPM took origin from middle $1 / 3^{\text {rd }}$ in $58.1 \%$ cases in males and $84.4 \%$ cases in females and from lower $1 / 3^{\text {rd }}$ in $41.9 \%$ cases in males and $6.3 \%$ cases in females. In females, PMPM arose from upper $1 / 3^{\text {rd }}$ of left ventricle in a small number of cases $(9.4 \%)$ but not so in males. The differences were statistically significant. Muscle bellies were intraluminal in $23.5 \%$ cases in males and $7.7 \%$ in females. Mixed types were found more often in males $(52.9 \%)$ than in females $(46.2 \%)$. Sessile muscle bellies occurred more in females.Muscle bellies were predominantly interlinked (26.7\%), mammillated (13.4\%), flat topped (10\%) and $\mathrm{H}$-shaped (10\%). The rest were saucerised, grooved (Fig 4.), arched, sloped, V shaped, $Y$ shaped (Fig.5), two tiered +1 separate, $V+1$ separate and three interlinked +1 separate (Table 3 ).

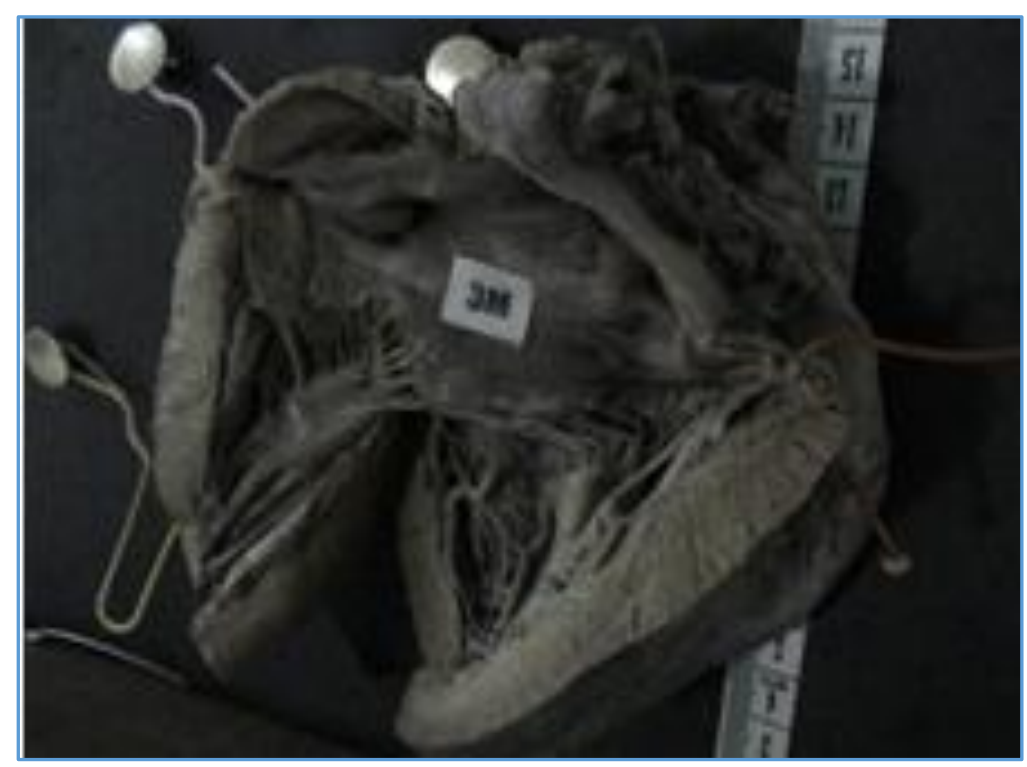

Figure 4. Grooved Posteromedial Papillary Muscle on Right Side of the Figure 


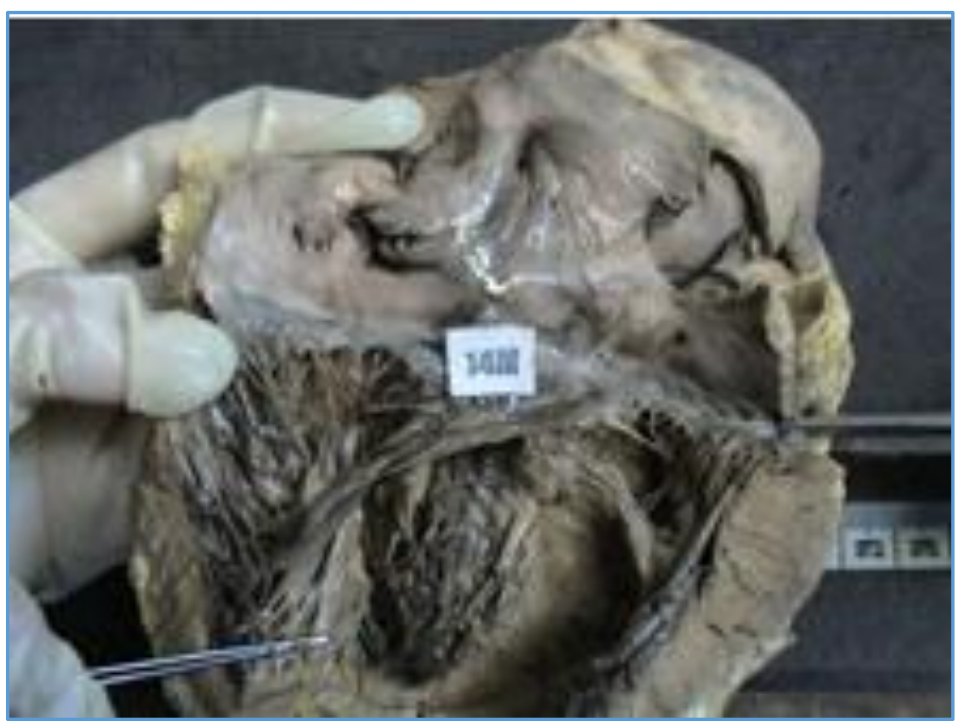

Figure 5. Y-Shaped Posteromedial Papillary Muscle on the Right Side of the Figure

\begin{tabular}{|c|c|c|c|c|c|c|c|c|c|c|c|}
\hline \multirow{2}{*}{$\begin{array}{l}\text { Papillary } \\
\text { Muscles }\end{array}$} & & \multirow{2}{*}{ Present } & \multirow{2}{*}{$\begin{array}{l}\text { No. of } \\
\text { Heads } \\
\text { Range }\end{array}$} & \multicolumn{2}{|c|}{ Length (mm) } & \multicolumn{3}{|c|}{ Origin } & \multicolumn{3}{|c|}{ Protrusion } \\
\hline & & & & Range & Mean & $\begin{array}{l}\text { Upper } \\
1 / 3\end{array}$ & $\begin{array}{c}\text { Middle } \\
1 / 3\end{array}$ & $\begin{array}{c}\text { Lower } \\
1 / 3\end{array}$ & $\begin{array}{l}\text { Intra- } \\
\text { luminal }\end{array}$ & Mixed & Sessile \\
\hline \multirow{4}{*}{$\begin{array}{l}\text { Anterolateral } \\
\text { (ALPM) }\end{array}$} & Total & $100.0 \%$ & $1-3$ & $8.3-45.5$ & $24.55 \pm 8.15$ & $4.7 \%$ & $52.4 \%$ & $42.9 \%$ & $10.0 \%$ & $73.3 \%$ & $16.7 \%$ \\
\hline & Male & $100.0 \%$ & $1-2$ & $8.6-45.5$ & $25.99 \pm 8.90$ & $0.0 \%$ & $50.0 \%$ & $50.0 \%$ & $17.6 \%$ & $58.8 \%$ & $23.6 \%$ \\
\hline & Female & $100.0 \%$ & $1-3$ & $8.3-40.0$ & $22.97 \pm 7.13$ & $10.0 \%$ & $55.0 \%$ & $35.0 \%$ & $0.0 \%$ & $92.3 \%$ & $7.7 \%$ \\
\hline & P-value & - & 0.246 & - & 0.234 & 0.101 & 0.475 & 0.669 & 0.118 & 0.041 & 0.264 \\
\hline \multirow{4}{*}{$\begin{array}{l}\text { Posteromedial } \\
\text { (PMPM) }\end{array}$} & Total & $100.0 \%$ & $1-6$ & $3.0-36.2$ & $19.71 \pm 8.28$ & $4.8 \%$ & $71.4 \%$ & $23.8 \%$ & $16.7 \%$ & $50.0 \%$ & $33.3 \%$ \\
\hline & Male & $100.0 \%$ & $1-4$ & $3.1-36.2$ & $22.60 \pm 8.33$ & $0.0 \%$ & $58.1 \%$ & $41.9 \%$ & $23.5 \%$ & $43.0 \%$ & $23.5 \%$ \\
\hline & Female & $100.0 \%$ & $1-6$ & $3.0-33.5$ & $16.91 \pm 7.31$ & $9.3 \%$ & $84.4 \%$ & $6.3 \%$ & $7.6 \%$ & $46.2 \%$ & $46.2 \%$ \\
\hline & P-value & - & 0.157 & - & 0.005 & 0.038 & 0.021 & 0.012 & 0.264 & 0.724 & 0.205 \\
\hline
\end{tabular}

\begin{tabular}{|c|c|c|c|c|}
\hline \multirow{2}{*}{ Papillary Muscles } & \multirow{2}{*}{ No. of Heads } & \multicolumn{3}{|c|}{ Length (mm) } \\
\hline & & Min & Max & Mean \\
\hline \multirow{3}{*}{ Anterolateral } & 1 & 16.7 & 45.5 & 28.8 \\
\hline & 2 & 8.6 & 40 & 22 \\
\hline & 3 & 8.3 & 26.8 & 15 \\
\hline \multirow{6}{*}{ Posteromedial } & 1 & 19.6 & 36.2 & 27.9 \\
\hline & 2 & 4.2 & 34.6 & 23.6 \\
\hline & 3 & 3 & 25.5 & 16.7 \\
\hline & 4 & 3.1 & 24.4 & 14.5 \\
\hline & 5 & - & - & - \\
\hline & 6 & 6.9 & 19.9 & 11.4 \\
\hline
\end{tabular}




\begin{tabular}{|c|c|c|c|c|c|}
\hline \multirow{2}{*}{ No. of Heads } & \multirow{2}{*}{ Pattern } & \multicolumn{2}{|c|}{ Anterolateral } & \multicolumn{2}{|c|}{ Posteromedial } \\
\hline & & No. of Cases & \%age & No. of Cases & \%age \\
\hline \multirow{9}{*}{1} & Conical & - & - & - & - \\
\hline & Mammillated & 6 & $20.0 \%$ & 4 & $13.4 \%$ \\
\hline & Flat topped & 8 & $26.7 \%$ & 3 & $10.0 \%$ \\
\hline & Grooved & 3 & $10.0 \%$ & 1 & $3.3 \%$ \\
\hline & Stepped & 1 & $3.3 \%$ & - & - \\
\hline & Wavy & - & - & - & - \\
\hline & Arched & - & - & 1 & $3.3 \%$ \\
\hline & Sloped & 1 & $3.3 \%$ & 1 & $3.3 \%$ \\
\hline & Saucerised & - & - & 2 & $6.7 \%$ \\
\hline \multirow{7}{*}{2} & 2 Tiered & 2 & $6.7 \%$ & - & - \\
\hline & Interlinked & 6 & $20.0 \%$ & 2 & $6.7 \%$ \\
\hline & Parallel & - & - & - & - \\
\hline & Arched & - & - & 0 & - \\
\hline & $\mathrm{V}$ & - & - & 2 & $6.7 \%$ \\
\hline & $\mathrm{Y}$ & - & - & 1 & $3.3 \%$ \\
\hline & $\mathrm{H}$ & 2 & $6.7 \%$ & 3 & $10.0 \%$ \\
\hline \multirow{6}{*}{3} & Parallel & - & - & - & - \\
\hline & Interlinked & - & - & 4 & $13.4 \%$ \\
\hline & 2 Interlinked + 1 Separate & - & - & - & - \\
\hline & Arched & - & - & - & - \\
\hline & 2 Tiered + Separate & 1 & $3.3 \%$ & 1 & $3.3 \%$ \\
\hline & V + 1 Separate & - & - & 2 & $6.7 \%$ \\
\hline \multirow{3}{*}{4} & Parallel & - & - & - & - \\
\hline & Interlinked & - & - & 1 & $3.3 \%$ \\
\hline & Interlinked + 1 Separate & - & - & 1 & $3.3 \%$ \\
\hline 5 & Interlinked & - & - & 1 & $3.3 \%$ \\
\hline \multicolumn{6}{|c|}{ Table 3. Shape of Papillary Muscles in Left Ventricle } \\
\hline
\end{tabular}

\begin{tabular}{|c|c|c|c|c|c|c|c|c|c|c|c|c|c|c|c|}
\hline \multirow{3}{*}{ 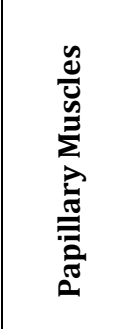 } & \multirow{3}{*}{ 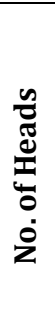 } & \multicolumn{7}{|c|}{ Present Study } & \multicolumn{7}{|c|}{ Victor \& Nayak ${ }^{15}$} \\
\hline & & \multirow[b]{2}{*}{ 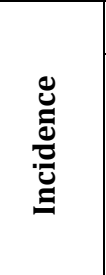 } & \multicolumn{3}{|c|}{ Origin } & \multicolumn{3}{|c|}{ Protrusion } & \multirow[b]{2}{*}{ 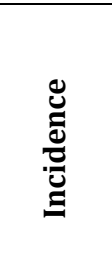 } & \multicolumn{3}{|c|}{ Origin } & \multicolumn{3}{|c|}{ Protrusion } \\
\hline & & & 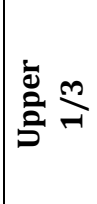 & $\frac{0}{\frac{0}{0}} \stackrel{n}{2}$ & 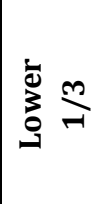 & 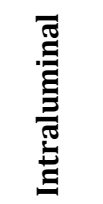 & : & 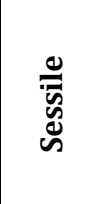 & & 㐫 & 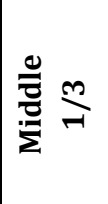 & 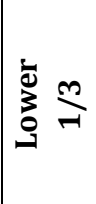 & 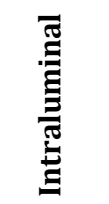 & 总 & $\begin{array}{l}\stackrel{0}{\bar{n}} \\
\dot{d} \\
\omega\end{array}$ \\
\hline \multirow{5}{*}{$\begin{array}{l}\text { Antero- } \\
\text { lateral }\end{array}$} & 1 & $63.4 \%$ & \multirow{5}{*}{$4.7 \%$} & \multirow{5}{*}{$52.4 \%$} & \multirow{5}{*}{$42.9 \%$} & \multirow{5}{*}{$10.0 \%$} & \multirow{5}{*}{$73.3 \%$} & \multirow{5}{*}{$16.7 \%$} & $67.0 \%$ & \multirow{5}{*}{$19.0 \%$} & \multirow{5}{*}{$79.5 \%$} & \multirow{5}{*}{$1.5 \%$} & \multirow{5}{*}{$33.0 \%$} & \multirow{5}{*}{$54.5 \%$} & \multirow{5}{*}{$12.5 \%$} \\
\hline & 2 & $33.3 \%$ & & & & & & & $27.0 \%$ & & & & & & \\
\hline & 3 & $3.3 \%$ & & & & & & & $4.0 \%$ & & & & & & \\
\hline & 4 & - & & & & & & & $1.0 \%$ & & & & & & \\
\hline & 5 & - & & & & & & & $1.0 \%$ & & & & & & \\
\hline \multirow{6}{*}{$\begin{array}{l}\text { Postero- } \\
\text { medial }\end{array}$} & 1 & $40.0 \%$ & \multirow{6}{*}{$4.8 \%$} & \multirow{6}{*}{$71.4 \%$} & \multirow{6}{*}{$23.8 \%$} & \multirow{6}{*}{$16.7 \%$} & \multirow{6}{*}{$50.0 \%$} & \multirow{6}{*}{$33.3 \%$} & $50.0 \%$ & \multirow{6}{*}{$6.0 \%$} & \multirow{6}{*}{$92.5 \%$} & \multirow{6}{*}{$1.5 \%$} & \multirow{6}{*}{$39.0 \%$} & & \\
\hline & 2 & $26.7 \%$ & & & & & & & $36.0 \%$ & & & & & & \\
\hline & 3 & $23.3 \%$ & & & & & & & $11.0 \%$ & & & & & $415 \%$ & $195 \%$ \\
\hline & 4 & $6.7 \%$ & & & & & & & $3.0 \%$ & & & & & $41.5 \%$ & $19.5 \%$ \\
\hline & 5 & - & & & & & & & - & & & & & & \\
\hline & 6 & $3.3 \%$ & & & & & & & - & & & & & & \\
\hline & & & Table & istrib & ind & o. of $\mathrm{H}$ & ds of & apillaı & Muscle & in Le & Ventr & & & & \\
\hline
\end{tabular}




\begin{tabular}{|c|c|c|c|c|c|}
\hline \multirow{2}{*}{$\begin{array}{l}\text { No. of } \\
\text { Heads }\end{array}$} & \multirow{2}{*}{ Pattern } & \multicolumn{2}{|c|}{ Present Study } & \multicolumn{2}{|c|}{ Victor \& Nayak ${ }^{15}$} \\
\hline & & Anterolateral & Posteromedial & Anterolateral & Posteromedial \\
\hline \multirow{9}{*}{1} & Conical & - & - & $32.0 \%$ & $12.0 \%$ \\
\hline & Mammillated & $20.0 \%$ & $13.4 \%$ & $14.0 \%$ & $12.0 \%$ \\
\hline & Flat topped & $26.7 \%$ & $10.0 \%$ & $9.0 \%$ & $8.0 \%$ \\
\hline & Grooved & $10.0 \%$ & $3.3 \%$ & $10.0 \%$ & $6.0 \%$ \\
\hline & Stepped & $3.3 \%$ & - & $2.0 \%$ & $5.0 \%$ \\
\hline & Wavy & - & - & - & $3.0 \%$ \\
\hline & Arched & - & $3.3 \%$ & - & $2.0 \%$ \\
\hline & Sloped & $3.3 \%$ & $3.3 \%$ & - & $1.0 \%$ \\
\hline & Saucerised & - & $6.7 \%$ & - & $1.0 \%$ \\
\hline \multirow{7}{*}{2} & 2 Tiered & $6.7 \%$ & - & $11.0 \%$ & $9.0 \%$ \\
\hline & Interlinked & $20.0 \%$ & $6.7 \%$ & $4.0 \%$ & $10.0 \%$ \\
\hline & Parallel & - & - & $7.0 \%$ & $6.0 \%$ \\
\hline & Arched & - & - & $1.0 \%$ & $5.0 \%$ \\
\hline & $\mathrm{V}$ & - & $6.7 \%$ & $1.0 \%$ & $4.0 \%$ \\
\hline & $\mathrm{Y}$ & - & $3.3 \%$ & $1.0 \%$ & $1.0 \%$ \\
\hline & $\mathrm{H}$ & $6.7 \%$ & $10.0 \%$ & $2.0 \%$ & $2.0 \%$ \\
\hline \multirow{6}{*}{3} & Parallel & - & - & $2.0 \%$ & $3.0 \%$ \\
\hline & Interlinked & - & $13.4 \%$ & - & $5.0 \%$ \\
\hline & 2 Interlinked + 1 Separate & - & - & $2.0 \%$ & - \\
\hline & Arched & - & - & - & $1.0 \%$ \\
\hline & 2 Tiered + 1 Separate & $3.3 \%$ & $3.3 \%$ & - & $1.0 \%$ \\
\hline & V+1 Separate & - & $6.7 \%$ & - & - \\
\hline \multirow{3}{*}{4} & Parallel & - & - & - & $2.0 \%$ \\
\hline & Interlinked & - & $3.3 \%$ & $1.0 \%$ & $1.0 \%$ \\
\hline & Interlinked + 1 Separate & - & $3.3 \%$ & - & - \\
\hline 5 & Scattered & - & - & $1.0 \%$ & - \\
\hline 6 & Interlinked & - & $3.3 \%$ & - & - \\
\hline \multicolumn{6}{|c|}{ Table 5. Shape of Papillary Muscles in Left Ventricle } \\
\hline
\end{tabular}

\section{DISCUSSION}

The present study was conducted on 30 human cadaveric hearts of North West Indians to note the morphology and morphometry of papillary muscles of left ventricle. There were 17 male and 13 female hearts ranging in age from 17 to 75 years in age. The incidence, number of heads, length, shape, origin, protrusion of muscle bellies of papillary muscles of left ventricle were noted in detail in both males and females in an attempt to find gender differences in papillary muscles. Both the papillary muscles of left ventricle were always present.

\section{Anterolateral Papillary Muscle (ALPM)}

Anterolateral papillary muscle was present in all the cases in the present study as well as in the other reports.8, 2,15, 16

Anterolateral papillary muscle has been described as being usually single (76.5\%), double in $12 \%$, triple in $7 \%$ and more than triple in only $4 \% .{ }^{17}$ Both the anterolateral and posteromedial papillary muscles have been described as having one or two distinct "bellies" of muscle and occasionally more than two. ${ }^{9}$ Number of heads of ALPM in the present study ranged from 1 to 3 , though $63.4 \%$ hearts showed only a single head. The range of number of heads was 1 to 5 in another Indian study ${ }^{8}$ with a single muscle in $67 \%$ cases (Table 4 ).

Single head ALPM were predominantly flat topped and mammillated types in the present study while in the other study, ${ }^{8}$ the predominant shape was conical and mammillated (Table 5). Double heads were mainly interlinked in the present study while they were mainly 2 -tiered and parallel in the study of Victor \& Nayak. ${ }^{8}$ Triple heads were 2-tiered +1 separate in our study of Northwest Indians whereas they were parallel and 2 interlinked +1 separate in South Indians. ${ }^{8}$

ALPM has been described as arising from the anterolateral free wall of left ventricle. ${ }^{1,6,7}$ It was from middle $1 / 3^{\text {rd }}$ of left ventricle in $52.4 \%$ of cases in the present study as compared to $79.5 \%$ in the other study. 8 The number of cases of ALPM taking origin from lower $1 / 3^{\text {rd }}$ of left ventricle was much more $(42.9 \%)$ as compared to that found by Victor and Nayak $(1.5 \%) .^{8}$

Papillary muscles of left ventricle were classified into three broad categories depending on the nature of attachment to the ventricular wall and the relative length of the body of the papillary muscle that protruded freely into the ventricular cavity. ${ }^{9}$ The categories are: completely tethered papillary muscle, finger like papillary muscle, mixed type papillary muscle. Protrusion of ALPM bellies into ventricular cavity was mixed type in $73.3 \%$ of cases as compared to $33 \%$ in the study by Victor and Nayak. ${ }^{8}$ Mixed type of ALPM was found more frequently in females (92.3\%) in the present study than in males (58.8\%). This difference was statistically significant $(\mathrm{p}<0.05)$.

Standard text books describe left ventricular papillary muscles as varying in length and breadth but no values have been given. ${ }^{2}$ Anterolateral papillary muscle has been described as slightly larger than posteromedial one.12 The findings of the present study are also the same as the mean length of ALPM was $24.55 \mathrm{~mm}$ and that of PMPM was 19.71 
mm. The mean length of anterolateral papillary muscles decreased as the number of heads increased.

\section{Posteromedial Papillary Muscles (PMPM)}

Posteromedial papillary muscle was present in all the cases as stated in text books and other studies. ${ }^{8,2,15,16}$ PMPM has been described as having single head in $30 \%$, double in $26.5 \%$, triple in $37 \%$ and more than triple in $6 \% .{ }^{17}$ Number of heads of PMPM ranged from 1 to 6 in the present study with maximum cases of single head (40\%). Roberts and Cohen ${ }^{12}$ described left ventricular papillary muscle as having one major trunk from which an average of 6 'heads' project.

Shape of single head of PMPM was found to be predominantly mammillated and flat topped in the present study. Double heads were predominantly $\mathrm{H}$ shaped, interlinked and V shaped. Victor and Nayak ${ }^{8}$ found mostly conical and mammillated bellies and mainly 2-tiered and interlinked double heads of PMPM (Table 5). Triple heads were mainly interlinked in the present study similar to that found by them. ${ }^{8}$ Four heads were interlinked and interlinked +1 separate in the present study while they were parallel and interlinked in the study of Victor and Nayak. ${ }^{8}$ Six heads were found only in the present study in one case. They were interlinked type.

PMPM has been described as arising from the junction of posterior wall and interventricular septum.1, 6, 7 Brock $^{6}$ reported left ventricular papillary muscles as arising from the ventricular wall at junction of apical and middle thirds. This position permits the contracting papillary muscles to exert a desirable vertical force on the chordae tendineae, effectively moving the leaflets together during isovolumetric contraction and restraining them during ventricular ejection. ${ }^{18,} 19$ Posteromedial papillary muscle (PMPM) showed significant gender differences in origin in the present study. Posteromedial papillary muscle of the left ventricle took origin mainly from middle $1 / 3^{\text {rd }}$ of left ventricle (Table 1 ). Such cases occurred more frequently in females than in males. The difference was statistically significant $(p<0.05)$. Origin of posteromedial papillary muscle from lower $1 / 3^{\text {rd }}$ of left ventricle was more in males than in females. This difference was also statistically significant $(\mathrm{p}<0.05)$. In females, the origin of posteromedial papillary muscle was from upper $1 / 3^{\text {rd }}$ of left ventricle also in a small number of cases but not so in males. This difference was also statistically significant $(\mathrm{p}<0.05)$.

Protrusion of muscle bellies of PMPM was mainly mixed type in both the studies but the incidence was higher in the present study. Intraluminal muscle bellies were less frequent in the present study (16.7\%) than in the study by Victor and Nayak $^{8}(39 \%)$. Sessile muscle bellies were more common in the present study (33.3\%).

The mean length of PMPM was found to decrease as the number of heads increased (Table 2).

Mean length of ALPM was more as compared to that of posteromedial papillary muscle. This can be explained by the fact that anterolateral papillary muscle arose from lower $1 / 3^{\text {rd }}$ of left ventricle more frequently than posteromedial papillary muscle and therefore in order to reach the mitral valve, it has to be longer than posteromedial papillary muscle.

\section{CONCLUSIONS}

The present study was done with a purpose to find out the gross morphology and size of papillary muscles in left ventricles and compare our findings with other studies and note any racial or gender differences among them. The morphometry of papillary muscles is very useful during mitral valve repair. In the present study, the incidence, number of heads, length, shape, origin, protrusion of muscle bellies of papillary muscles of left ventricles were noted in detail in both males and females.

Number of heads of papillary muscles ranged from 1 to 6 in left ventricle. In left ventricle, both the papillary muscles were longer in males than in females. The difference was statistically significant in case of posteromedial papillary muscle. Mean length of papillary muscles was found to decrease in the present study as the number of heads increased. Posteromedial papillary muscle (PMPM) showed gender differences in its origin in the present study. Posteromedial papillary muscle of the left ventricle took origin mainly from middle $1 / 3^{\text {rd }}$ of left ventricle. Such cases occurred more frequently in females than in males. The difference was statistically significant $(\mathrm{p}<0.05)$. Origin of posteromedial papillary muscle from lower $1 / 3^{\text {rd }}$ of left ventricle was more in males than in females. This difference was also statistically significant $(\mathrm{p}<0.05)$. In females, origin of posteromedial papillary muscle was also from upper $1 / 3^{\text {rd }}$ of left ventricle in a small number of cases but not so in males. This difference was also statistically significant $(\mathrm{p}<0.05)$.

Thus, a detailed knowledge of anatomical characteristics of the papillary muscles of the ventricles is necessary because of their clinical and surgical significance. Very few Indian studies have been done on morphometric analysis of papillary muscles. The purpose of present study is to extend concepts previously presented as well as to overcome deficiencies in our knowledge of anatomy of papillary muscles in Indian population.

\section{Acknowledgement}

It is with deep sense of gratitude and reverence that I express my sincere thanks to my guide Dr. Balbir Singh, Professor, Department of Anatomy, Chhattisgarh Institute of Medical Sciences and my co-guides Dr. Kanchan Kapoor and Dr. Mahesh Sharma, Professors, Department of Anatomy, Government Medical College, Chandigarh for allowing me to undertake this study. I am thankful to Dr Daisy Sahni, Department of Anatomy, PGIMER, Chandigarh for her valuable help.

\section{REFERENCES}

1. Burch GE, DePasquale NP, Phillips JH. The syndrome of papillary muscle dysfunction. Am Heart J 1968;75(3):399415.

2. Williams PL, Warwick R, Dyson M. Gray's anatomy. 37th edn. London: Churchill Livingstone 1989:p. 703-11.

3. Ranganathan N, Lam JHC, Wigle ED, et al. Morphology of the human mitral valve: II. The valve leaflets. Circulation 1970;41(3):459-67.

4. Harken DE, Ellis LB, Dexter L, et al. The responsibility of the physician in the selection of patients with mitral stenosis for surgical treatment. Circulation 1952;5(3):349-62. 
5. Rusted IE, Scheifley CH, Edwards JE. Studies of the mitral valve. I. Anatomic features of the normal mitral valve and associated structures. Circulation 1952;6(6):825-31.

6. Brock RC. The surgical and pathological anatomy of the mitral valve. Br Heart J 1952;14(4):489-513.

7. Estes EH, Dalton FM, Entman ML, et al. The anatomy and blood supply of the papillary muscles of the left ventricle. Am Heart J 1966;71(3):356-62.

8. Victor S, Nayak VM. Variations in the papillary muscles of the normal mitral valve and their surgical relevance. J Card Surg 1995;10(5):597-607.

9. Ranganathan N, Burch GE. Gross morphology and arterial supply of the papillary muscles of the left ventricle of man. Am Heart J 1969;77(4):506-16.

10. Ronan JA, Steelman RB, deLeon AC, et al. The clinical diagnosis of acute severe mitral insufficiency. Am J Cardiol 1971;27(3):284-90.

11. Morrow AG, Cohen LS, Roberts WC, et al. Severe mitral regurgitation following acute myocardial infarction and ruptured papillary muscle: hemodynamic findings and results of operative treatment in four patients. Circulation 1968;37(4 suppl):II124-32.
12. Roberts WC, Cohen LS. Left ventricular papillary muscles. Description of the normal and a survey of conditions causing them to be abnormal. Circulation 1972;46(1):13854.

13. Grant RP. Architectonics of the heart. Am Heart J 1953;46(3):405-31.

14. Walmsley T, ed. Quain's anatomy. $11^{\text {th }}$ edn. Vol. IV. part III. London: Longmans, Green and Co 1929.

15. Walls EW. The blood vascular and lymphatic systems. In: Romanes GJ, ed. Cunningham's textbook of anatomy. $12^{\text {th }}$ edn. Oxford: Oxford University Press 1981:p. 880-5.

16. Rosse C, Gaddum-Rosse P. Hollinshead's textbook of anatomy. $5^{\text {th }}$ edn. Philadelphia: Lippincott-Raven Publishers 1997:p. 473-6.

17. Rusted IE, Scheifley CH, Edwards JE, et al. Guides to the commissures in operations upon the mitral valve. Proc Staff Meet Mayo Clin 1951;26(16):297-305.

18. Levy MJ, Edwards JE. Anatomy of mitral insufficiency. Progr Cardiovasc Dis 1962;5:119-44.

19. Shelburne JC, Rubinstein D, Gorlin R. A reappraisal of papillary muscle dysfunction; correlative clinical and angiographic study. Am J Med 1969;46(6):862-71. 